\title{
Case report of a novel phenotype in $18 q$ deletion syndrome
}

\author{
Roxana Elena BohÎltea ${ }^{1,2)}$, Monica Mihaela CîrstoiU ${ }^{1,2)}$, Florina Mihaela Nedelea ${ }^{3)}$, \\ NATALIA TURCAN ${ }^{1,2)}$, TiBeRIU AUGUSTIN GEORGESCU ${ }^{4}$, OCTAVIAN MUNTEANU ${ }^{2,5}$, \\ ALEXANDRU BAROŞ ${ }^{1,2)}$, ANCA-MARIA ISTRATE-OFITERU ${ }^{6,7)}$, COSTIN BERCEANU6) \\ 1) Department of Obstetrics and Gynecology, Carol Davila University of Medicine and Pharmacy, Bucharest, \\ Romania \\ 2) Department of Obstetrics and Gynecology, University Emergency Hospital Bucharest, Romania \\ 3) Department of Medical Genetics, Carol Davila University of Medicine and Pharmacy, Bucharest, Romania \\ 4) Department of Pathology, Carol Davila University of Medicine and Pharmacy, Bucharest, Romania \\ 5) Department of Anatomy, Carol Davila University of Medicine and Pharmacy, Bucharest, Romania \\ 6) Department of Obstetrics and Gynecology, University of Medicine and Pharmacy of Craiova, Romania \\ 7)Department of Histology, University of Medicine and Pharmacy of Craiova, Romania
}

\begin{abstract}
The latest decades are characterized by an enormous progression in the field of human genetics. In consequences, for various phenotypic manifestations, genetic testing could identify a specific underlying cause. An estimated incidence for all types of $18 q$ deletions is one in 55000 births predominant on females. About $94 \%$ of cases with $18 \mathrm{q}$ deletion syndrome appearance are de novo, and the remaining $6 \%$ are the inherited from a parent carrying a balanced chromosomal translocation. We present the case of a 35 -year-old female who was admitted in our Unit for a second ultrasound opinion after being diagnosed at the second trimester scan at gestational age of 21 weeks of pregnancy with multiple brain and heart malformations, having the recommendation for fetal magnetic resonance imaging (MRI). Further investigations included genetic analysis and pathological examination. Major malformations diagnosed and confirmed were agenesis of the corpus callosum, ventriculomegaly with dilated fourth ventricle, partial agenesis of vermis, bilateral anophthalmia with wide nasal base and left cleft lip. Additional, cardiac malformation, with an important ventricular septal defect and overriding aorta were noted. The results of the microarray analysis showed an abnormal fetal karyotype with a loss of 30.5 basis identified in the long arm of chromosome 18. Although most of the cases of $18 \mathrm{q}$ deletion are sporadically or de novo, could be cases where the possible existing syndromes can be inherited from a healthy or mild affected parent. Therefore, in order to establish the recurrence risk, parental karyotypes are recommended.
\end{abstract}

Keywords: 18q deletion, human genetics, ultrasound, Pitt-Hopkins syndrome.

\section{Introduction}

The latest decades have been characterized by an enormous progression in the field of human genetics. In consequence, various phenotypic manifestations require genetic testing in order to identify the specific underlying cause.

The group of conditions which may be encountered due to deletion of different regions and size of a certain portion in the long (q) arm of the chromosome 18 can vary widely, depending on involved genes. An estimated incidence for all types of 18q deletions is one in 55000 births, with highly variable phenotype and slight predominance in females [1], but this value does not cover the uninvestigated conception products obtained from spontaneous or required abortions or uninvestigated cases of fetuses with mild pathological features. In most of the cases, about $94 \%$ with $18 \mathrm{q}$ deletion syndrome appearance is de novo, and the remaining $6 \%$ are inherited from a parent carrying a balanced chromosomal translocation [1].

The phenotypical manifestation of the $18 \mathrm{q}$ deletion syndrome varies significantly according to the involved region. The proximal 18q deletion has specific manifes- tations including cardiac abnormalities, hydronephrosis, development delay, vision impairment and hypotonia [2]. In these cases, the involved region is between megabase positions 20 and 45.7, which comprises up to 80 genes, including the SET binding protein 1 (SETBP1) gene, which is responsive for expressive speech development [3].

The distal region is formed from 103 genes, respectively the region at the end of the chromosome 18. The more frequent terminal region presents important variations. The number of affected genes can be single or involves all the distal region [4], knowing the specific involved genes is essential for future management. If the transcription factor 4 (TCF4) gene is implied in the deletion, the clinical manifestation will imply breathing disabilities, distinctive facial dysmorphic features like skunked eyes, high nasal bridge and thick and cup-shaped ears, recurrent seizures, and intellectual and development delay [5]. Those findings are named Pitt-Hopkins syndrome which includes microcephaly, myopia, short stature, brain abnormalities and small hand and feet with pes planus [6]. To date, this syndrome was described in only 500 cases worldwide [7]. If the TCF4 gene is not included in the deleted sequence, the deletion will manifest with vision and hearing problems,

This is an open-access article distributed under the terms of a Creative Commons Attribution-NonCommercial-ShareAlike 4.0 International Public License, which permits unrestricted use, adaptation, distribution and reproduction in any medium, non-commercially, provided the new creations are licensed under identical terms as the original work and the original work is properly cited. 
limb deformities, delayed development, and deficiency of the growth hormone [8].

\section{Aim}

In this paper, we report an extremely rare case of a second trimester pregnancy with complex cranio-cephalic and cardiac malformations, which turned out to be a case of $18 \mathrm{q}$ deletion syndrome. Subsequent array comparative genomic hybridization $(\mathrm{CGH})$ revealed the following karyotype: arr [GRCh37] 18q21.1q23 (47427490_7801 3728) $\mathrm{x} 1$. The fetus presented unusual phenotypic traits, such as bilateral anophthalmia and cardiac malformations, which to our knowledge have not been previously described in $18 \mathrm{q}$ deletion syndrome or associated with a specific breakpoint related to this syndrome. We compared autopsy and genetic findings with current literature data and elaborated a brief literature analysis.

\section{Case presentation}

A 35-year-old female was admitted for second ultrasound opinion after being diagnosed at the second trimester scan at gestational age of 21 weeks of pregnancy with multiple brain and heart malformations. The patient received the recommendation for fetal magnetic resonance imaging (MRI) and appropriate management. From the personal medical history, we mention one spontaneous first trimester abortion and one therapeutic abortion at 13 weeks of gestation in the context of an increased nuchal translucency and high suspicion of chromosomal syndrome. No family history or personal history of genetic diseases was noted, and the patient and her partner had normal karyotypes.

At the moment of the admission, a detailed fetal sonographic exam was performed, evidencing a single, live fetus of 23 weeks of gestation chronologically with an early intrauterine growth restriction of three weeks and severe oligohydramnios. Multiple cranial-cephalic malformations were noted as: agenesis of the corpus callosum, ventriculomegaly with dilated IV $^{\text {th }}$ ventricle, partial agenesis of vermis, bilateral anophthalmia with wide nasal base and left cleft lip. Additional, cardiac malformation, with an important ventricular septal defect and overriding aorta were also observed.

The fetal MRI exam confirmed all cranial-cephalic malformations diagnosed sonographic.

The case was the subject of debate within a specialized Commission and by presenting and explaining to the patient the presumptive diagnosis, the Commission offered the possibility of therapeutic abortion with a subsequent genetic analysis, with which the patient agrees. The procedure went without significant incidents, giving the patient psychological support before and after the procedure. A sample of fetal tissue and maternal blood was sent in the same day for the genetic analysis and the product of the conception with the trophoblast were sent for pathological examination.

\section{Array CGH}

Microarray test was performed using CytoScan $750 \mathrm{~K}$ Arrays, GeneScan 3000 (Affymetrix). The genomic data were analyzed with Chromosome Analysis Suite (ChAS) Software. The method (microarray) allows the detection of genetic material imbalances, microdeletions or micro- duplications greater than $100 \mathrm{~kb}$, located in the genomic regions associated with all known syndromes.

Results of the microarray analysis: arr [GRCh37] 18q21.1q23 (47427490_78013728) x1.

An abnormal fetal result with a loss of 30.5 basis was identified in the long arm of chromosome 18, in the region $18 \mathrm{q} 21.1 \rightarrow 18 \mathrm{q} 23$. According with the analyzed databases, the described genomic imbalance has pathogenic significance. The deletion region is responsible for the occurrence of 18q (OMIM * 601808) deletion syndrome. The consequences are clinically variable, among the most common phenotypic aspects being small stature, intellectual disabilities, learning difficulties, hypotonia, hearing problems, microcephaly, cleft lip and palate, foot anomalies and heart malformations.

\section{Autopsy report}

Permission for autopsy was obtained from the family and the product of conception with umbilical cord and placenta were sent to the Department of Pathology for histopathological (HP) evaluation.

The fetus was $18 \mathrm{~cm}$ tall and weighed approximately $200 \mathrm{~g}$, with very poor physical constitution considering the gestational age. The cranial perimeter was $19 \mathrm{~cm}$, and the thoracic perimeter was $14 \mathrm{~cm}$. Anterior fontanelle measured $3 \times 1.5 \mathrm{~cm}$ and the posterior fontanelle measured $1 \times 1 \mathrm{~cm}$. The umbilical cord was intact, edematous, and measured $16 \times 0.8 \mathrm{~cm}$. No umbilical cord knots or tangles were present. The umbilical cord linked the fetus to a discoidal placenta with clear membranes and no signs of hematoma or infarction, measuring $11 \times 9.5 \times 2 \mathrm{~cm}$ and weighing approximately $100 \mathrm{~g}$ (Figure 1).

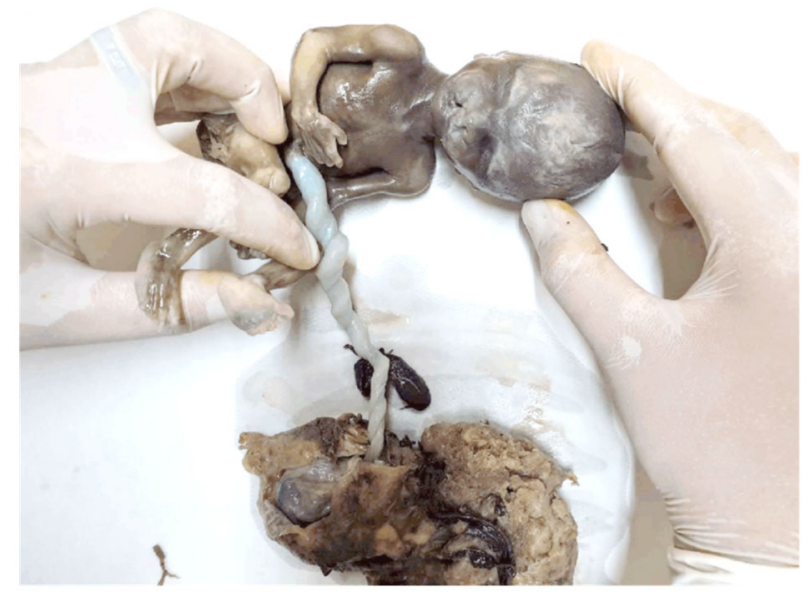

Figure 1 - Gross aspect of the product of conception, umbilical cord and placenta received in the Department of Pathology for autopsy and histopathological examination.

Upon inspection of the fetus, the most striking morphological defects were the presence of a cleft lip on the right side, bilateral anophthalmia with wide nasal base and low implantation of the ears. The eyelids appeared normal, but the lachrymal puncta were absent. The palpebral apertures were sealed, and no vestigial ocular globe could be identified. Interestingly, the orbital cavities seemed to be smaller than normal. The anal orifice was permeable and external genital organs appeared normal, indicating a female. No additional gross malformations were noted (Figure 2). 


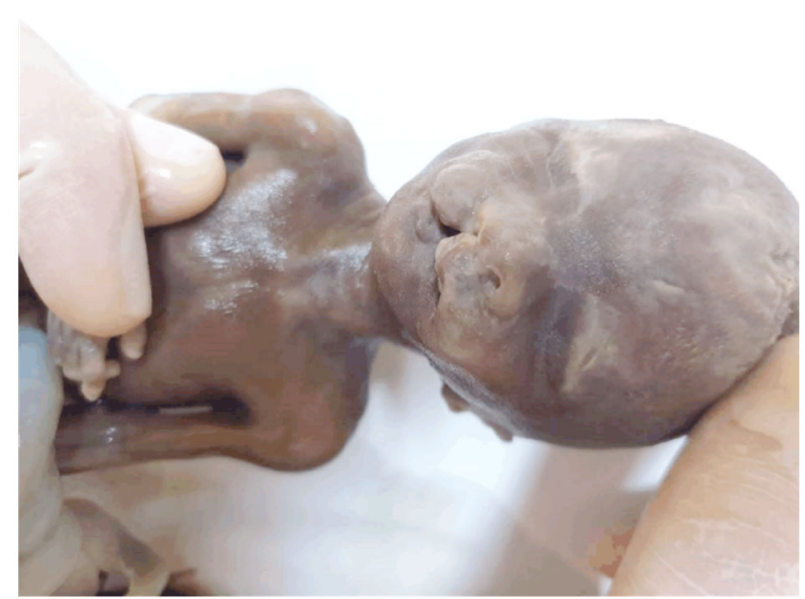

Figure 2 - Gross aspect of the fetus highlighting the craniofacial defects observed during autopsy: bilateral anophthalmia, cleft lip and low implantation of the ears.

Cerebrospinal fluid was clear with few slightly red streaks. The meninges were transparent, with prominent vessels. The brain appeared normal and partially convoluted on its superior and lateral aspects, while the base showed complete absence of the chiasma and optic tracts. The brainstem was removed from the cerebral hemispheres through a section at the level of the midbrain. The cerebral hemispheres were bisected along the mid-sagittal plane and revealed ventriculomegaly with dilatation of the IV ${ }^{\text {th }}$ ventricle and agenesis of the corpus callosum (Figure 3 ). The separate hemispheres were placed back together, followed by coronal sectioning. Each slice was submitted for histological examination. The brain stem and cerebellum were sectioned along the sagittal plane. Upon HP examination, serial sections in the frontal plane of the brain hemispheres revealed no trace of optic tracts, as well as no histological features of a lateral geniculate nucleus. There were no abnormalities of the basal ganglia, their fibrous tracts, or of the internal capsule.
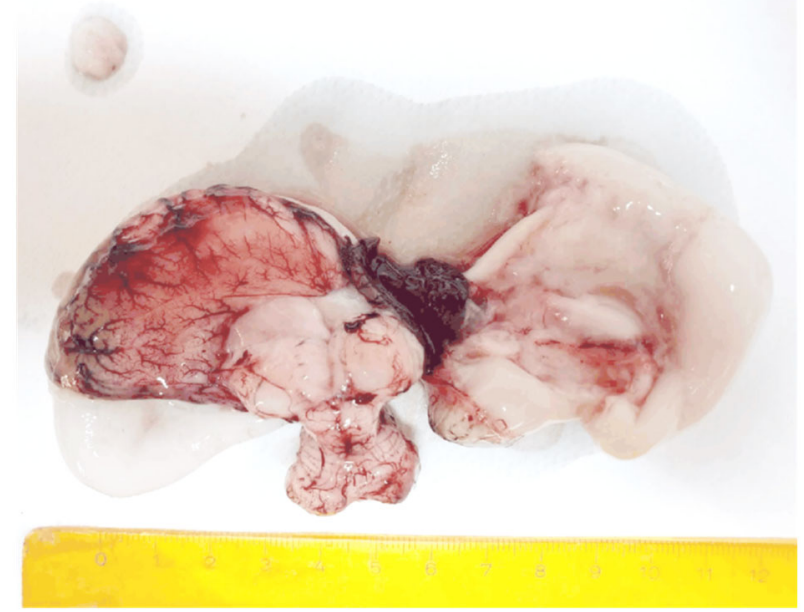

Figure 3 - Gross aspect of the fetal brain showing congested meninges, dilatation of the I $V^{\text {th }}$ ventricle and partial agenesis of the vermis.

Both the left and right pleural cavities contained $10 \mathrm{~mL}$ of cloudy yellow colored liquid. The left and right lungs featured normal lobar conformation and weighed $21 \mathrm{~g}$ and $32 \mathrm{~g}$, respectively. HP examination of the lungs revealed late canalicular stage of evolution with severe pulmonary congestion and thickening of the pulmonary arterioles.
We also noted capillaries pushing into the airways and forming the first blood-air barriers (Figure 4).

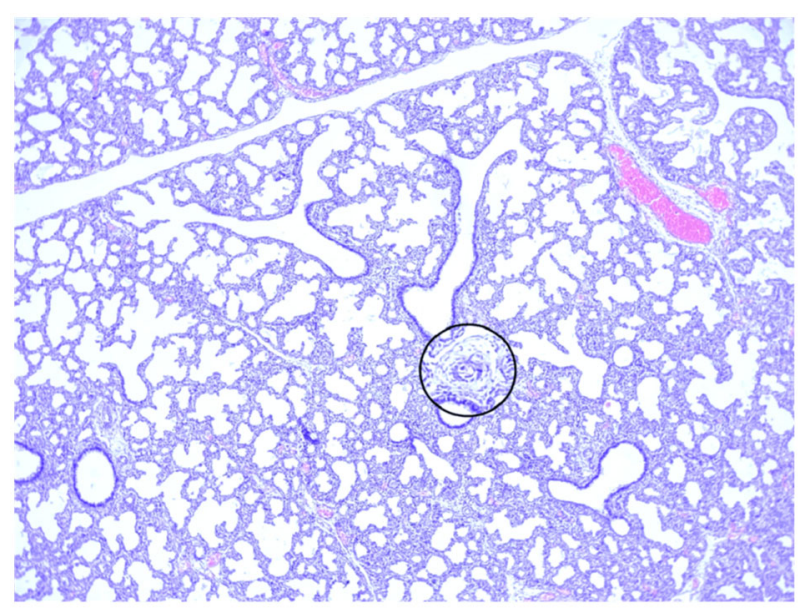

Figure 4 - Histopathological micrograph of the fetal lung showing late canalicular stage of evolution with marked thickening of the pulmonary arterioles (HE staining, $\times 100$ ).

The pericardial sac revealed approximately $5 \mathrm{~mL}$ of clear fluid. The heart measured $3 \times 2 \times 1 \mathrm{~cm}$ and weighed $34 \mathrm{~g}$, with a left ventricular wall thickness of $0.3 \mathrm{~cm}$. The right ventricle was moderately dilated. A peri-membranous ventricular septal defect measuring $0.3 \times 0.2 \mathrm{~cm}$ with overriding aorta was identified. Cardiac blood was in liquid state, without clot formation (Figure 5). HP examination revealed that both the left and right ventricular muscles were thickened. Endocardium covering both the ventricles and septum was also mildly thickened. The sinus node, atrioventricular node, and the bundle of His all appeared normal (Figure 6).

The peritoneal cavity was distended by approximately $15 \mathrm{~mL}$ of clear serous-citrine liquid. The main organs within the abdominal cavity were in their normal anatomical location, cyanotic and engorged with blood. The liver was almost normal, except for mild congestion. HP examination revealed multiple foci of extramedullary hematopoiesis and areas of micro-vesicular steatosis (Figure 7).

The upper urinary system appeared histologically normal, with preserved fetal lobulation of both kidneys and permeable ureter on each side. Right kidney with adrenal gland measured $4 \times 0.8 \times 0.7 \mathrm{~cm}$ and left kidney with adrenal gland measured $3 \times 0.8 \times 0.7 \mathrm{~cm}$. Both pairs of organs were cyanotic and engorged with blood (Figure 8). Examination of the lower urinary system revealed a hypoplastic bladder and permeable urethra.

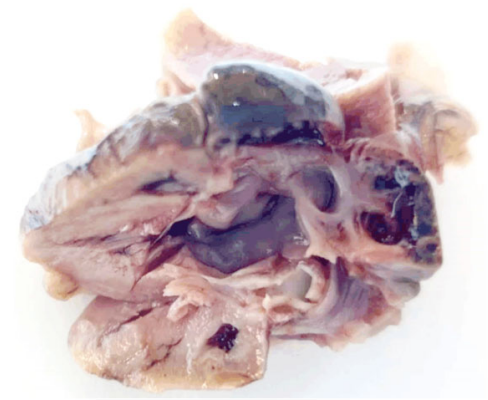

Figure 5 - Gross aspect of the fetal myocardium showing moderate thickening of the left ventricular wall and dilatation of the right ventricular chamber. 


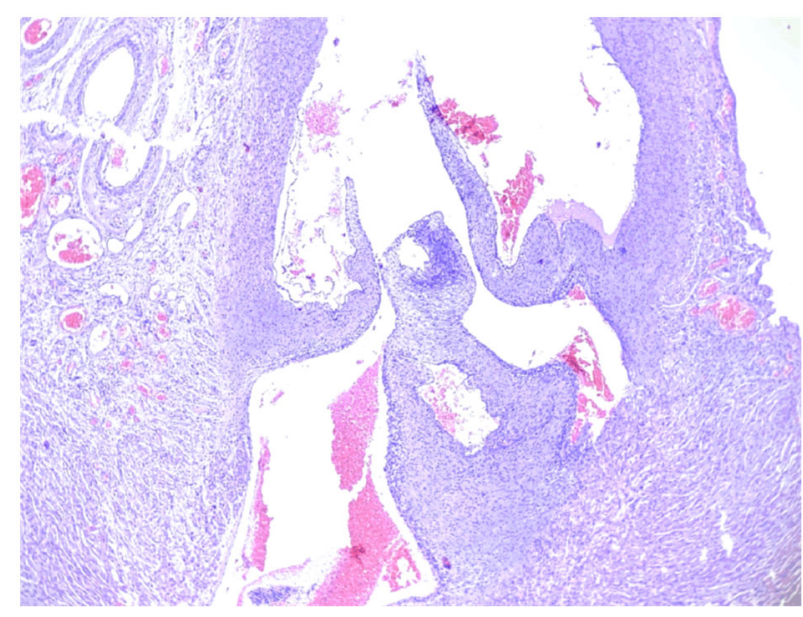

Figure 6 - Histopathological micrograph of the fetal myocardium, showing the emergence of the aorta and interventricular septum (HE staining, $\times 40)$.

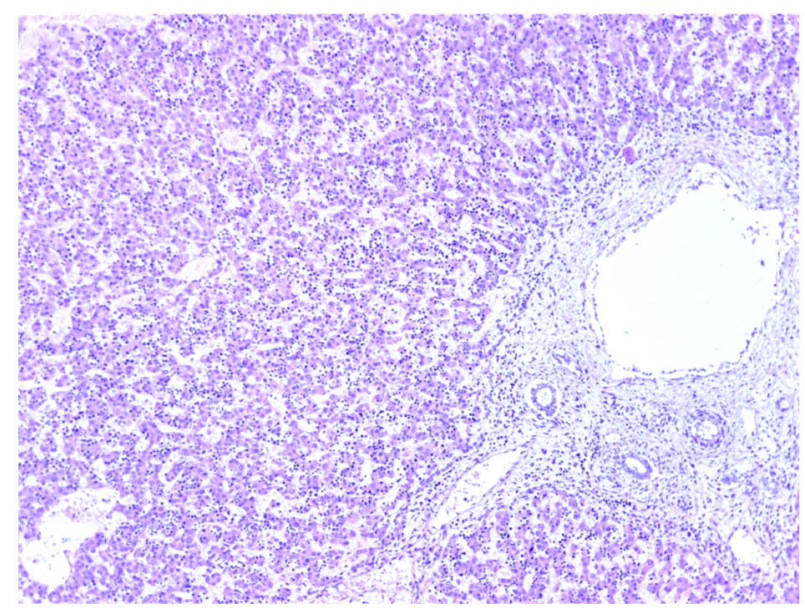

Figure 7 - Histopathological micrograph of the fetal liver, showing a distended portal tract and multiple foci of extramedullary hematopoiesis (HE staining, $\times 100)$.
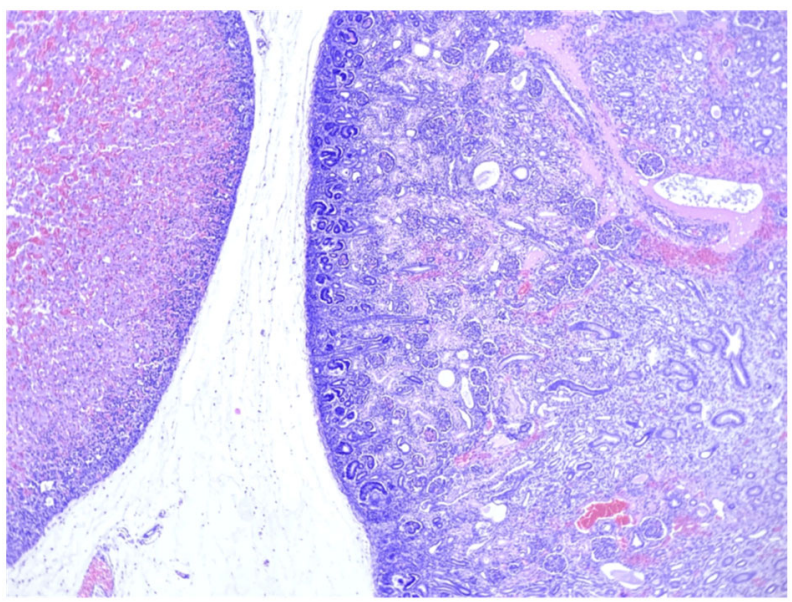

Figure 8 - Histopathological micrograph of the kidney (right) and adrenal gland (left) showing features of subcapsular nephrogenesis in various stages of evolution and vascular congestion (HE staining, $\times 40)$.

Examination of internal genital organs confirmed female phenotype. The uterine corpus, ovaries and Fallopian tubes were present and within normal limits both grossly and microscopically (Figure 9).

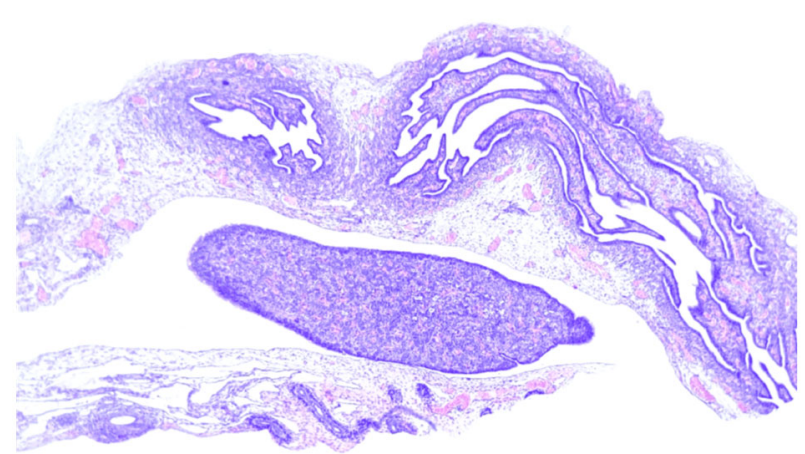

Figure 9 - Fetal ovary covered by a single layer of cuboidal cells with well-developed cortex, composed of primordial germinal cells, oogonia with syncytial distribution and rare primordial follicles (HE staining, $\times 40$ ).

\section{• Discussions}

The $18 \mathrm{q}$ deletion syndrome is sometimes called $18 \mathrm{q}-$ syndrome, de Grouchy syndrome or monosomy $18 \mathrm{q}$ and was first described in 1963 by the French geneticist Jean de Grouchy [9]. Although patients with deletions of the long arm of chromosome 18 display a wide range of phenotypic traits, there are enough similarities to define the loss of part of chromosome $18 \mathrm{q}$ as a syndrome [10]. Therefore, most people with $18 \mathrm{q}$ deletion syndrome are missing a different, but often overlapping, portion of chromosome 18 [11]. This would mean that each individual would be missing a different set of genes. In order to correlate these phenotypic attributes with various chromosomal anomalies, previous studies have compared the molecular karyotyping results obtained by array $\mathrm{CGH}$ with clinical features of patients with $18 \mathrm{q}$ deletion [12]. The 29 patient samples evaluated by Feenstra et al. in 2007 [12] identified different breakpoints, thus confirming previous hypotheses that there is no breakage hotspot involved in $18 \mathrm{q}$ deletions [13]. In 1993, the study published by Kline et al. defined a critical region for microcephaly to be located between $18 \mathrm{q} 21.2$ and 18q21.3 [14]. Cleft palate with or without cleft lip appears to be one of the main features of patients with $18 \mathrm{q}$ deletions and was also present in our case. Previous studies indicate a proximal critical region located in 18q12.1-q12.3 (25.2-42.9 basis) and a distal critical region located in 18q22.3-23 (67.7-74.9 basis) [12].

No major cardiac malformations related to $18 \mathrm{q}$ deletion syndrome have been previously reported in the scientific literature. Kim et al. published a case of de novo $18 \mathrm{q}$ deletion syndrome with karyotype 46,XX,del(18)(q22.1) featuring a large atrial septal defect (ASD) and cyanosis. Except for the large ASD, the phenotype of their case was relatively mild compared with other cases of $18 \mathrm{q}$ deletion syndrome having similar deletion sizes [15]. Along with their findings, our case provisions a possible relationship between $18 \mathrm{q}$ terminal deletion and atrioventricular septal defects, which could be useful for further studies on genotype-phenotype correlations between $18 \mathrm{q}$ deletion syndrome and cardiac anomalies.

Chromosome 18q-syndrome is also often characterized by additional eye (ocular) defects, such as vertical skin folds that may cover the eyes' inner corners (epicanthic folds); involuntary, rhythmic, rapid eye movements (nystagmus); 
and/or abnormal deviation of one eye in relation to the other (strabismus). Associated ocular defects may also include abnormally small eyes (microphthalmia); partial absence of ocular tissue from the colored region of the eyes (coloboma of the iris); clouding of the normally transparent front region of the eyes (corneal opacities); defects of the retinas and optic disks; and/or other ocular abnormalities. (The retina is the nerve-rich membrane upon which images are focused on the back of the eye; its specialized nerve cells convert light into nerve impulses that are transmitted to the brain via the optic nerve. The optic disk, also known as the "blind spot", is the region where fibers of the retina become part of the optic nerve.) Such ocular defects may result in varying degrees of visual impairment. Bilateral anophthalmia associated in $18 \mathrm{q}$ deletion syndrome, however there was not yet been described in the scientific literature, being rather present in deletions of chromosome 14q.

Holoprosencephaly can be present in about $15 \%$ of cases with $18 \mathrm{p}$ deletion syndrome, this manifestation being related with the lift/palate structural defects $[16,17]$.

According to the array $\mathrm{CGH}$ genetic results, the deleted region also included the TCF4 gene, located at $18 \mathrm{q} 21.1$, which is responsible of associated signs and symptoms of Pitt-Hopkins syndrome, as severe intellectual disability and breathing problems [6]. Pitt-Hopkins syndrome is a rare, genetic, neurological disorder which was first described by Pitt \& Hopkins in 1978 [7]. A syndrome of mental retardation, wide mouth, and intermittent over-breathing, but its underlying genetic defect has eluded the scientific community until 2007 [18], when it was linked to a haploinsufficiency of the TCF4 gene, located on the long arm of chromosome 18 (18q21.2).

Approximately 50 cases have been reported worldwide, males and females being equally affected. Although not incompatible with life, Pitt-Hopkins syndrome involves severe neurological deficit. Patients share distinctive facial features and experience severe intellectual disabilities, with delays in reaching developmental milestones, impaired ability to speak, tendency to epilepsy, breathing pattern anomalies, stereotypic movements, constipation, and high myopia.

An interesting historical aspect of this syndrome has recently emerged from Professor Philip Beales [12], of the Institute of Child Health who speculated that Peter the Wild Boy suffered from Pitt-Hopkins syndrome. Peter the Wild Boy was a boy of unknown parentage, who was found in 1725 living an entirely feral existence for an unknown length of time in the woods near Hamelin, northern Germany, surviving by eating forest flora. Without getting into details regarding his intriguing life, he exhibited several behavioral aspects that are worth mentioning: he walked on all fours, demonstrated uncivilized behavior, and could not be taught to speak a language.

Although most of the cases of $18 \mathrm{q}$ deletion are sporadically or de novo, could be cases where the possible existing syndromes can be inherited from a healthy or mild affected parent. Therefore, in order to establish the recurrence risk, parental karyotypes are recommended.

\section{ㅁ Conclusions}

The clinicopathological spectrum of $18 \mathrm{q}$ deletion syndrome is extremely variable and incompletely elucidated to date, requiring further research. Certain karyotypes have been demonstrated to be associated with specific phenotypic traits. Our case report reveals novel morphological defects such as bilateral anophthalmia and complex cardiac malformations which to the best of our knowledge have not been previously described in $18 \mathrm{q}$ deletion syndrome. Taking into consideration the high variability of clinical features in patients with $18 \mathrm{q}$ deletion syndrome, we believe that molecular karyotyping is mandatory in order to establish this diagnosis and accurately determine the incidence of this disease.

\section{Conflict of interests}

The authors declare that they have no conflict of interests.

\section{References}

[1] Wellesley D, Dolk H, Boyd PA, Greenlees R, Haeusler M, Nelen V, Garne E, Khoshnood B, Doray B, Rissmann A, Mullaney C, Calzolari E, Bakker M, Salvador J, Addor MC, Draper E, Rankin J, Tucker D. Rare chromosome abnormalities, prevalence and prenatal diagnosis rates from population-based congenital anomaly registers in Europe. Eur J Hum Genet, 2012, 20(5):521-526. https://doi.org/10.1038/ejhg.2011.246 PMID: 22234154 PMCID: PMC3330224

[2] Filges I, Shimojima K, Okamoto N, Röthlisberger B, Weber P, Huber AR, Nishizawa T, Datta AN, Miny P, Yamamoto T. Reduced expression by SETBP1 haploinsufficiency causes developmental and expressive language delay indicating a phenotype distinct from Schinzel-Giedion syndrome. J Med Genet, 2011, 48(2):117-122. https://doi.org/10.1136/jmg.2010. 084582 PMID: 21037274

[3] Marseglia G, Scordo MR, Pescucci C, Nannetti G, Biagini E, Scandurra V, Gerundino F, Magi A, Benelli M, Torricelli F. $372 \mathrm{~kb}$ microdeletion in 18q12.3 causing SETBP1 haploinsufficiency associated with mild mental retardation and expressive speech impairment. Eur J Med Genet, 2012, 55(3): 216-221. https://doi.org/10.1016/j.ejmg.2012.01.005 PMID: 22333924

[4] Heard PL, Carter EM, Crandall AC, Sebold C, Hale DE, Cody JD. High resolution genomic analysis of $18 q$ - using oligo-microarray comparative genomic hybridization (aCGH). Am J Med Genet Part A, 2009, 149A(7):1431-1437. https://doi.org/10.1002/ ajmg.a.32900 PMID: 19533772 PMCID: PMC2731576

[5] Brockschmidt A, Todt U, Ryu S, Hoischen A, Landwehr C, Birnbaum S, Frenck W, Radlwimmer B, Lichter P, Engels $\mathrm{H}$, Driever W, Kubisch C, Weber RG. Severe mental retardation with breathing abnormalities (Pitt-Hopkins syndrome) is caused by haploinsufficiency of the neuronal bHLH transcription factor TCF4. Hum Mol Genet, 2007, 16(12):1488-1494. https://doi. org/10.1093/hmg/ddm099 PMID: 17478476

[6] Sweatt JD. Pitt-Hopkins syndrome: intellectual disability due to loss of TCF4-regulated gene transcription. Exp Mol Med, 2013, 45(5):e21. https://doi.org/10.1038/emm.2013.32 PMID: 23640545 PMCID: PMC3674405

[7] Van Balkom IDC, Vuijk PJ, Franssens M, Hoek HW, Hennekam RCM. Development, cognition, and behaviour in Pitt-Hopkins syndrome. Dev Med Child Neurol, 2012, 54(10):925-931. https://doi.org/10.1111/j.1469-8749.2012.04 339.x PMID: 22712893

[8] Hasi M, Soileau B, Sebold C, Hill A, Hale DE, O'Donnell L, Cody JD. The role of the TCF4 gene in the phenotype of individuals with $18 q$ segmental deletions. Hum Genet, 2011, 130(6):777-787. https://doi.org/10.1007/s00439-011-1020-y PMID: 21671075 PMCID: PMC3215814

[9] de Grouchy J, Lamy M, Thieffry S, Arthuis M, Salmon Ch. Dysmorphie complexe avec oligophrénie: délétion des bras courts d'un chromosome 17-18. C R Acad Sci (Paris), 1963, 256:1028-1029.

[10] Brandigi E, Molinaro F, Bulotta AL, Angotti R, Pavone M, Messina M. Chromosome 18q-syndrome and $1 p$ terminal duplication in a patient with bilateral vesico-ureteral reflux: case report and literature revision. Ital J Pediatr, 2013, 39:6. https://doi.org/10.1186/1824-7288-39-6 PMID: 23343423 PMCID: PMC3599261 
[11] Kim YM, Cho EH, Kim JM, Lee MH, Park SY, Ryu HM. Del(18p) syndrome with increased nuchal translucency in prenatal diagnosis. Prenat Diagn, 2004, 24(3):161-164. https:// doi.org/10.1002/pd.741 PMID: 15057945

[12] Feenstra I, Vissers LELM, Orsel M, Van Kessel AG, Brunner HG, Veltman JA, Van Ravenswaaij-Arts CMA. Genotype-phenotype mapping of chromosome $18 q$ deletions by high-resolution array $\mathrm{CGH}$ : an update of the phenotypic map. Am J Med Genet A 2007, 143A(16):1858-1867. https://doi.org/10.1002/ajmg.a. 31850 PMID: 17632778

[13] Strathdee G, Zackai EH, Shapiro R, Kamholz J, Overhauser J. Analysis of clinical variation seen in patients with $18 q$ terminal deletions. Am J Med Genet, 1995, 59(4):476-483. https://doi. org/10.1002/ajmg.1320590414 PMID: 8585568

[14] Kline AD, White ME, Wapner R, Rojas K, Biesecker LG, Kamholz J, Zackai EH, Muenke M, Scott Cl Jr, Overhauser J. Molecular analysis of the 18q- syndrome - and correlation with phenotype. Am J Hum Genet, 1993, 52(5):895-906. PMID: 8488839 PMCID: PMC1682039

[15] Kim YJ, Park TS, Han MY, Yoon HS, Choi YS. A Korean case of de novo 18q deletion syndrome with a large atrial septal defect and cyanosis. Ann Lab Med, 2015, 35(2):272-274. https://doi.org/10.3343/alm.2015.35.2.272 PMID: 25729737 PMCID: PMC4330185

[16] Turleau C. Monosomy 18p. Orphanet J Rare Dis, 2008, 3:4 https://doi.org/10.1186/1750-1172-3-4 PMID: 18284672 PMCID: PMC2265258

[17] Portnoï MF, Gruchy N, Marlin S, Finkel L, Denoyelle F, Dubourg C, Odent S, Siffroi JP, Le Bouc Y, Houang M. Midline defects in deletion 18p syndrome: clinical and molecular characterization of three patients. Clin Dysmorphol, 2007, 16(4):247-252. https://doi.org/10.1097/MCD.0b013e328235 a572 PMID: 17786116

[18] Amiel J, Rio M, de Pontual L, Redon R, Malan V, Boddaert N, Plouin $\mathrm{P}$, Carter NP, Lyonnet S, Munnich A, Colleaux L. Mutations in TCF4, encoding a class I basic helix-loop-helix transcription factor, are responsible for Pitt-Hopkins syndrome, a severe epileptic encephalopathy associated with autonomic dysfunction. Am J Hum Genet, 2007, 80(5):988-993. https:// doi.org/10.1086/515582 PMID: 17436254 PMCID: PMC1852736

\section{Corresponding authors}

Octavian Munteanu, Assistant Professor, MD, PhD, Department of Anatomy, Carol Davila University of Medicine and Pharmacy, 8 Eroilor Sanitari Avenue, Sector 5, 050474 Bucharest, Romania; Phone: +40722-650 092, e-mail: octav_munteanu@yahoo.com

Tiberiu Augustin Georgescu, Assistant Professor, MD, PhD, Department of Pathology, Carol Davila University of Medicine and Pharmacy, 8 Eroilor Sanitari Avenue, Sector 5, 050474 Bucharest, Romania; Phone +40721-868 622, e-mail: tiberiuaugustin.georgescu@gmail.com 